\title{
Selective Oxidation of Olefins Catalyzed by Polymer-anchored Nickel(II) Complex in Water Medium
}

\author{
Manirul Islam, ' Dildar Hossain, Paramita Mondal, Anupam Singha Roy, Sanchita Mondal, and Manir Mobarak \\ Department of Chemistry, University of Kalyani, Kalyani, Nadia, 741235,W.B., India. *E-mail: manir65@rediffmail.com \\ Received June 24, 2010, Accepted October 19, 2010
}

\begin{abstract}
Selective oxidation of olefins has been carried out in water medium with tert-butylhydroperoxide (TBHP, $70 \%$ aqueous) as an oxidant using polymer-anchored Ni(II) complex as a catalyst. Several parameters were varied to optimize the reaction conditions. Under the optimized reaction conditions olefins gave selectively allylic oxidation products. The present polymer anchored $\mathrm{Ni}$ (II) complex can be recycled five times without any appreciable loss in catalytic activity.
\end{abstract}

Key Words: Chloromethylated polystyrene, Nickel (II) complex, Olefin oxidation, Water, TBHP

\section{Introduction}

In the chemical processes, traditional organic solvents are used in large quantities, which has led to various environmental and health concerns. As part of green chemistry efforts, a variety of cleaner solvents have been evaluated as replacements. ${ }^{1,2}$ As an alternative solvent, water has paid extraordinary attention because it is not only inexpensive and environmentally benign, but also shows unique reactivity and selectivity. ${ }^{3-6}$ Phase transfer catalysis is becoming an interestingly important technique in organic synthesis. But there is one limitation in this method that many phase transer catalysts promote stable emulsion which render work-up difficult. Regen introduced the new concept of triphase catalysis, in which the catalst and each of a pair of reagents are located in separate phase. ${ }^{7,8}$ The major advantage of triphase catalysis over phase transfer catalysis is that the catalyst can be removed from the reaction mixture by simple filtration. Based on the above two concepts, we tried to synthesize a polymer anchored metal complex which catalyze the organic reactions in aqueous medium without any phase transfer catalyst.

The use of heterogeneous catalysts for oxidation reaction has paid much attention to reducing waste, thus working towards an environmentally benign chemical process. Homogeneous catalysts possess higher efficiency and are suitable for study of the reaction mechanism but their higher susceptibility to drastic reaction conditions and the difficulties associated with their isolation from the product mixture restrict their reusability. These disadvantages can be overcome by immobilized metal on suitable supports. The anchoring of metal on solid support not only exhibits improved catalyst stability and selectivity of the product but also enables easy recovery and reuse of the catalyst. ${ }^{9,10}$ Chloromethylated polystyrene cross linked with divinylbenzene is one of the most widely employed macromolecular supports for immobilization of homogeneous catalyst. ${ }^{11-15}$ Polymer-anchored transition metal complexes were found to be efficient catalysts for the oxidation of various olefins. ${ }^{16-20}$ Allylic oxidation of olefins into unsaturated ketones and alcohols is an important reaction in organic synthesis. ${ }^{21,22}$ Allylic oxidation products of alkenes are important in organic synthesis, and in the manufacture of perfumery, pharmaceutical, dyestuff and agrochemicals. $^{23,24}$

The aim of our work is to explore an alternative process for synthesis of various allylic oxidation products and provided clean and environmentally benign way for commercial production. In our present study, we have developed a more active and recyclable heterogeneous nickel(II) catalyst for aerobic oxidation of olefins in environmentally friendly water medium. This catalyst afforded high conversions for the oxidation of various olefins in an aqueous medium at $60{ }^{\circ} \mathrm{C}$ in presence of TBHP as oxidant. Furthermore, it was found that the solid catalyst could be reused five times without significant loss of its catalytic activity.

\section{Experimental}

All chemicals and solvents were analytical grade, commercially available and used without further purification. Morphology of polymer-anchored ligand and polymer-anchored metal complex were analyzed using a Jeol JSM 6700 scanning electron microscope. The thermal stability of the immobilized catalyst was determined using a Mettler Toledo TGA/SDTA 851. The FTIR spectrum of the immobilized [PS-Ni-AMP] catalyst was recorded on a Perkin-Elmer FTIR 783 spectrophotometer using $\mathrm{KBr}$ pellets. Diffuse reflectance UV-vis spectra were taken using a Shimadzu UV-2401PC doubled beam spectrophotometer having an integrating sphere attachment for solid samples. The metal loadings on the polymeric support were analyzed using a Varian AA240 atomic absorption spectrophotometer (AAS).

The liquid phase oxidation reactions were carried out in two-necked round bottom flask fitted with a water condenser and placed in an oil bath at prearranged temperature under continuous stirring. The oxidation was carried out as follows: catalyst $(0.050 \mathrm{~g})$, water $(10 \mathrm{~mL})$, substrate $(5 \mathrm{mmol})$, and TBHP $(10 \mathrm{mmol})$ were charged in the reaction flask When the reaction was completed, the organic products were separated from the aqueous phase by extraction with dichloromethane $(3 \times 10 \mathrm{~mL})$, and then the combined organic portion were concentrated and analyzed by using Varian 3400 gas chromatograph equipped with a $30 \mathrm{~m}$ CP-SIL-8CB capillary column and a flame ioniza- 
<smiles>CC(C)C(C)c1ccc(N)cc1</smiles>

(1)

(P)=Polystyrene Framework

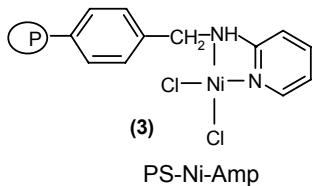

Polymer-anchored Ni(II) complex

Scheme 1

tion detector. All reaction products were identified by using an Agilent GC-MS (QP-5050).

The outline for the preparation of polymer-anchored Ni(II) complex, [PS-Ni-AMP], is given in Scheme 1. The polymer anchored ligand (2) was prepared by covalently attachment of 2-aminopyridine $(1.4 \mathrm{~g})$ with chloromethylated polystyrene $(1.0 \mathrm{~g})$ in $15 \mathrm{~mL}$ dioxane according to literature..$^{25}$ In the next step, the polymer-anchored 2-amino pyridine $(2.0 \mathrm{~g})$ was allowed to stir in $20 \mathrm{~mL}$ of methanol for $2 \mathrm{~h}$ prior to the reaction. A $10 \mathrm{~mL}$ methanolic solution of $\mathrm{NiCl}_{2}(0.3 \mathrm{~g})$ was added to the above suspension and the reaction mixture was refluxed at $50{ }^{\circ} \mathrm{C}$ for $24 \mathrm{~h}$. After cooling to room temperature the light green color metal complex (3) was separated by filtration, washed thoroughly with methanol and water and finally dried under vacuum.

\section{Results and Discussion}

Due to insolubility of the [PS-Ni-AMP] catalyst in all common organic solvents, its structural investigation was limited to its physicochemical properties, chemical analysis, SEM, TGA, IR and UV-vis spectral data. Chemical analyses results suggest $1.65 \mathrm{wt} \% \mathrm{Ni}$ in the immobilized Ni(II) complex.

Scanning electron micrographs (SEM) of [PS-AMP] ligand (Fig. 1A) and [PS-Ni-AMP] catalyst (Fig. 1B) were recorded to understand the morphological change occurred on the surface of the polymer matrix. The pure chloromethylated polystyrene bead had a smooth surface (not shown in Fig.). After coordination with ligand, a slight roughing on the polymer surface was observed in the SEM picture. This roughing became relatively more after complexation with metal. This is possibly due to interaction of the metal ions with anchored ligands that resulted in the formation of the complex. Also presence of metal along with carbon and chlorine can be further proved by energy dispersive spectroscopy analysis of X-rays (EDX) (Fig. 2) which suggests the immobilization of metal complex into the polymer matrix.

The mode of attachment of 2-amino pyridine and metal onto the polymeric support was confirmed by IR spectral bands both in the mid $\left(4000-400 \mathrm{~cm}^{-1}\right)$ and far $\left(600-50 \mathrm{~cm}^{-1}\right)$ IR regions. The IR spectra of ligand and corresponding metal complex are presented in Fig. 3. The formation of polymer bound 2-amino-
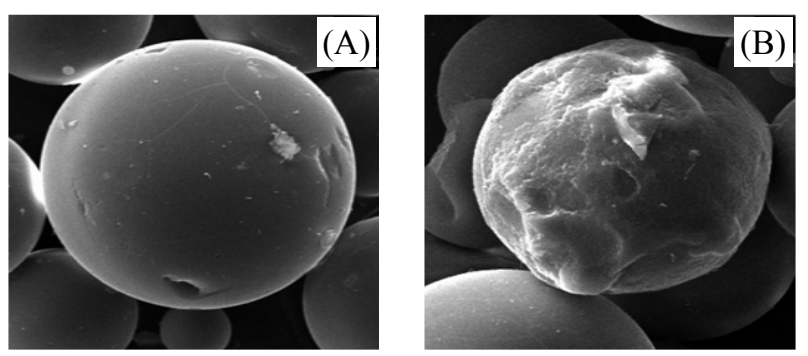

Figure 1. SEM image of [PS-AMP] ligand (A) and [PS-Ni-AMP] catalyst (B).

(A)

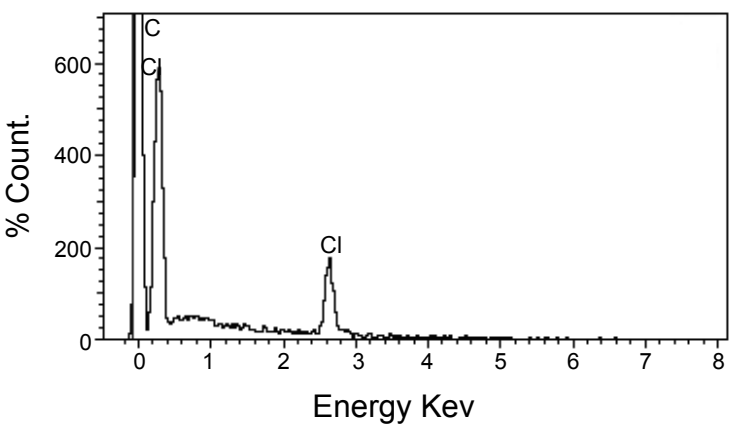

(B)

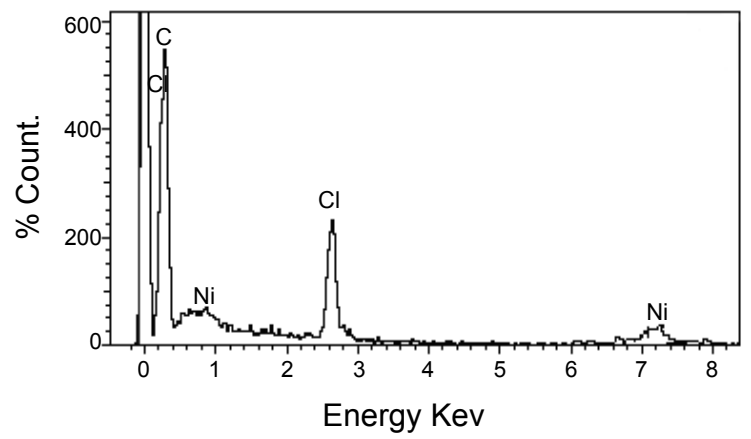

Figure 2. EDX spectra of [PS-AMP] ligand (A) and [PS-Ni-AMP] catalyst (B).

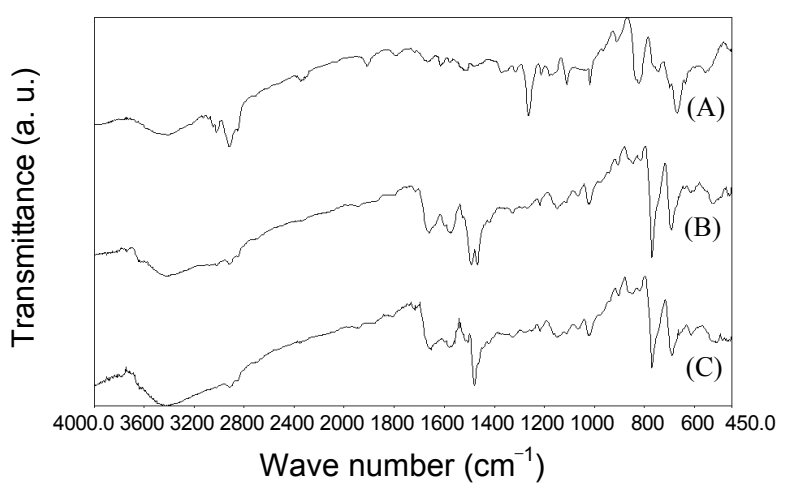

Figure 3. FT-IR spectra of chloromethylated polystyrene (A), [PSAMP] ligand (B) and [PS-Ni-AMP] catalyst (C).

pyridine ligand confirmed by the disappearance of the peak at $1266 \mathrm{~cm}^{-1}$ corresponded to the $\mathrm{H}-\mathrm{C}-\mathrm{Cl}$ vibration mode of the original chloromethylated resin ${ }^{26}$ and the appearance of a strong band due to sec-amine (NH) stretching vibration presents in the 
region $1650-1660 \mathrm{~cm}^{-1}$. The polymer-anchored ligand exhibited medium to broad intensity bands in the region 3100 -

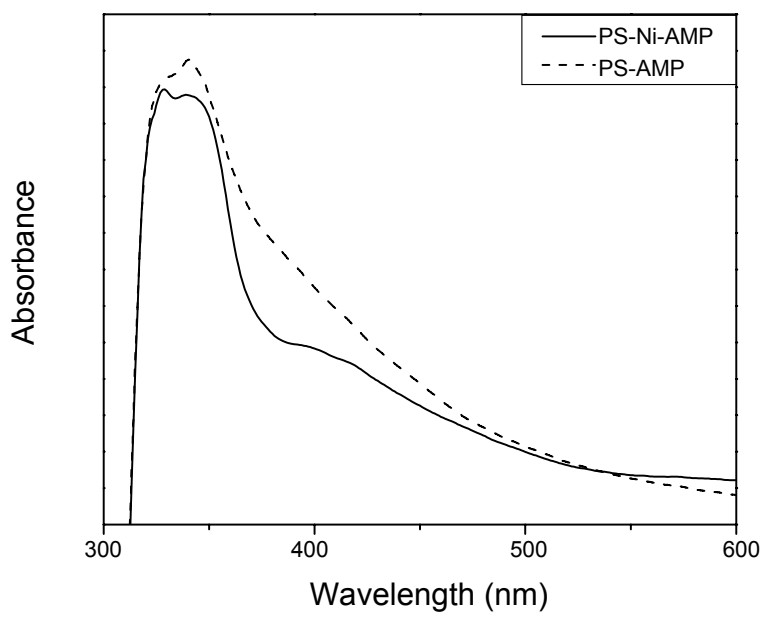

Figure 4. DRS-UV-visible absorption spectra of [PS-AMP] ligand and [PS-Ni-AMP] catalyst.

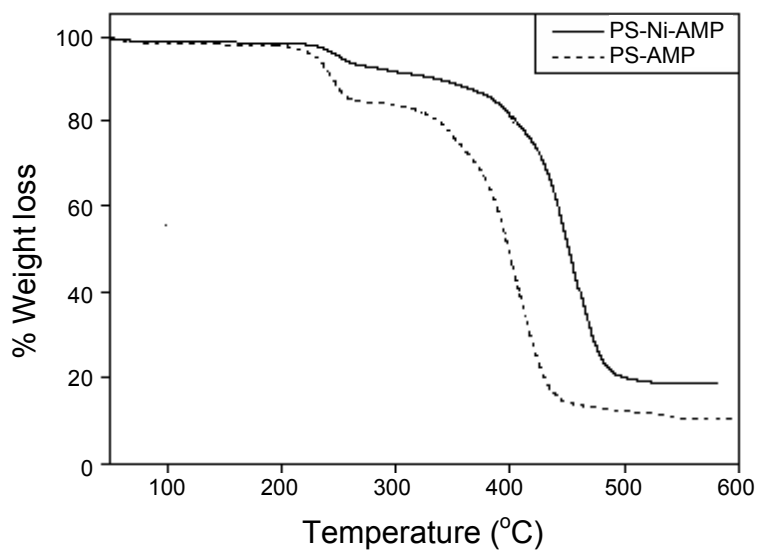

Figure 5. TGA curves of [PS-AMP] ligand and [PS-Ni-AMP] catalyst.
3500 assigned to the $\mathrm{NH}$ stretch as well as the $\mathrm{CH}$ stretching mode of the pyridine. Pyridyl ring breathing vibrations were observed as strong bands in the region $1400-1600 \mathrm{~cm}^{-1} .{ }^{27}$ Slight shifting towards lower frequency in these bands suggests the co-ordination through the nitrogen of pyridine ring. More conclusive information on the coordination of the ligand to the central metal ion comes from the new bands due to $v(\mathrm{Ni}-\mathrm{N})$ $240 \mathrm{~cm}^{-1}$ (pyridine nitrogen), ${ }^{28} v(\mathrm{Ni}-\mathrm{N}) 208 \mathrm{~cm}^{-1}$ (secondary nitrogen) and $v(\mathrm{Ni}-\mathrm{Cl}) 247 \mathrm{~cm}^{-1} \cdot{ }^{29}$

The electronic spectrum of the [PS-Ni-AMP] catalyst and [PS-AMP] ligand were recorded in the diffuse reflectance spectrum mode as $\mathrm{a} \mathrm{BaSO}_{4}$ disc. Fig. 4 shows that bands at $329 \mathrm{~nm}$ and $342 \mathrm{~nm}$ were assigned to the imine $\pi \rightarrow \pi^{*}$ and $n \rightarrow \pi^{*}$ transition of pyridine moiety. ${ }^{30}$ In the complex, the bands around $387-423 \mathrm{~nm}$ may be assigned to d-d transition due to presence of $\mathrm{Ni}(\mathrm{II})$ ion. $^{31}$

Thermal stability of the [PS-AMP] ligand and [PS-Ni-AMP] catalyst were investigated at a heating rate of $10^{\circ} \mathrm{C} / \mathrm{min}$ in air over a temperature range of $30-600{ }^{\circ} \mathrm{C}$. Fig. 5 shows that the polymer-anchored ligand decomposed at $320^{\circ} \mathrm{C}$ where as the polymer-anchored metal complex degrades at slightly higher temperature at $370{ }^{\circ} \mathrm{C}$.

The catalytic activity of [PS-Ni-AMP] catalyst was investigated by oxidation of olefins. In order to optimize the reaction conditions, the effects of various reaction parameters such as solvent, oxidant, reaction temperature, catalyst concentration and substrate-to-oxidant ratio were studied taking oxidation of styrene as a probe reaction. During the catalytic oxidation of styrene, benzaldehyde and acetophenone were identified as products (Scheme 2).
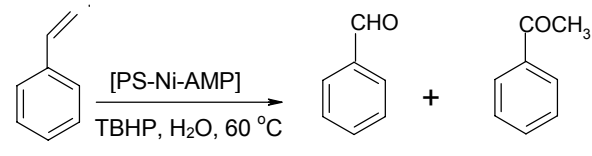

Major

Minor

Scheme 2

Table 1. Optimized reaction conditions for the oxidation of styrene using PS-Ni-AMP catalyst ${ }^{a}$

\begin{tabular}{|c|c|c|c|c|c|c|}
\hline Entry & Solvent & Oxidant & $\begin{array}{c}\text { Catalyst } \\
\text { Amount }(\mathrm{g})\end{array}$ & Substrate: oxidant & Conversion $^{b}(\%)$ & $\begin{array}{c}\text { Selectivity }^{b} \\
\text { of benzaldehyde (\%) }\end{array}$ \\
\hline 1 & $\mathrm{ACN}$ & ТВНР & 0.05 & $1: 2$ & 82 & 30 \\
\hline 2 & $\mathrm{CH}_{2} \mathrm{Cl}_{2}$ & ТВHP & 0.05 & $1: 2$ & 55 & 40 \\
\hline 3 & $\mathrm{MeOH}$ & ТВНР & 0.05 & $1: 2$ & 70 & 73 \\
\hline 4 & $\mathrm{H}_{2} \mathrm{O}$ & ТВНР & 0.05 & $1: 2$ & 95 & 93 \\
\hline 5 & $\mathrm{H}_{2} \mathrm{O}$ & $\mathrm{H}_{2} \mathrm{O}_{2}$ & 0.05 & $1: 2$ & 27 & 40 \\
\hline 6 & $\mathrm{H}_{2} \mathrm{O}$ & $\mathrm{PhIO}$ & 0.05 & $1: 2$ & 38 & 67 \\
\hline 7 & $\mathrm{H}_{2} \mathrm{O}$ & Cumene hydro peroxide & 0.05 & $1: 2$ & No conv. & - \\
\hline 8 & $\mathrm{H}_{2} \mathrm{O}$ & $\mathrm{Mol}_{\mathrm{O}} \mathrm{O}_{2}$ & 0.05 & $1: 2$ & 14 & 23 \\
\hline 9 & $\mathrm{H}_{2} \mathrm{O}$ & ТВНP & 0.025 & $1: 2$ & 53 & 90 \\
\hline 10 & $\mathrm{H}_{2} \mathrm{O}$ & ТВНP & 0.1 & $1: 2$ & 95 & 93 \\
\hline 11 & $\mathrm{H}_{2} \mathrm{O}$ & ТВНР & 0.05 & $1: 1$ & 37 & 87 \\
\hline 12 & $\mathrm{H}_{2} \mathrm{O}$ & ТВНР & 0.05 & $1: 3$ & 95 & 93 \\
\hline 13 & $\mathrm{H}_{2} \mathrm{O}$ & ТВНР & - & $1: 2$ & $6^{c}$ & 49 \\
\hline
\end{tabular}

${ }^{a}$ Reaction conditions: styrene $(5 \mathrm{mmol})$, solvent $(10 \mathrm{~mL})$, temperature $60{ }^{\circ} \mathrm{C}, 8 \mathrm{~h} .{ }^{b}$ Determined by GC and GC-MS. ${ }^{c}$ Blank reaction without catalyst. 
Table 1 (entries 1-4) illustrates the influence of the different solvents in the catalytic oxidation of styrene by [PS-Ni-AMP] catalyst. Water, acetonitrile (ACN), methanol $(\mathrm{MeOH})$ and dichloromethane $\left(\mathrm{CH}_{2} \mathrm{Cl}_{2}\right)$ were used as solvent. The highest conversion was obtained in water medium. The high conversion in water medium may be due to high polarity and dielectric constant of water than other solvents.

The effect of various oxidants e.g. TBHP, $\mathrm{H}_{2} \mathrm{O}_{2}$, PhIO, cumene hydroperoxide and molecular oxygen, were investigated in styrene oxidation reaction. The results are summarized in Table 1. From the results it was seen that when molecular oxygen used as oxidant, very low conversion of styrene to benzaldehyde was obtained (entry 8). No conversion was found with cumene hydroperoxide as oxidant (entry 7). TBHP was found to be the best oxidant in present catalytic oxidation reaction (entry 4). Oxidants like $\mathrm{H}_{2} \mathrm{O}_{2}$ and $\mathrm{PhIO}$ were clearly less efficient than TBHP (Entries 5, 6).

The effect of temperature on the performance of catalyst was studied in the temperature range $30-70{ }^{\circ} \mathrm{C}$ at a fixed amount of styrene ( $5 \mathrm{mmol})$, TBHP (10 mmol), PS-Ni-AMP (50 mg) in

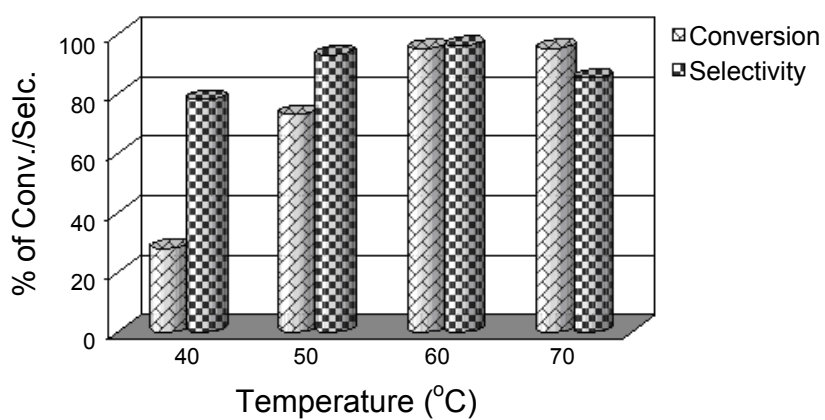

Figure 6. Effect of temperature on the oxidation of styrene using [PSNi-AMP] catalyst. Reaction condition: [styrene] $=5 \mathrm{mmol}$, [TBHP] $=$ $10 \mathrm{mmol}$, Catalyst $(0.05 \mathrm{~g}), \mathrm{H}_{2} \mathrm{O}(10 \mathrm{~mL})$, time $(8 \mathrm{~h})$.
$10 \mathrm{~mL}$ water (Fig. 6). At room temperature $\left(30^{\circ} \mathrm{C}\right)$ no conversion of styrene was obtained. The optimum temperature was found to be $60{ }^{\circ} \mathrm{C}$ as maximum conversion of $95 \%$ was achieved at this temperature. Lower temperatures $\left(40\right.$ and $\left.50{ }^{\circ} \mathrm{C}\right)$ did not favor the oxidation reaction and at high temperature $\left(70^{\circ} \mathrm{C}\right)$, the selectivity of benzaldehyde decreases.

The activity of the [PS-Ni-AMP] complex in the oxidation of styrene was evaluated using three different molar ratios of styrene-to-TBHP (entries 4 and 11, 12). Using a styrene-toTBHP molar ratio 1:2, 95\% conversion of styrene to benzaldehyde was obtained but a low conversion of styrene was obtained when styrene-to-TBHP molar ratio 1:1 was taken. On further increasing this ratio to $1: 3$, the conversion was hardly affected. From the results, it was suggested that 1:2 ratio of styrene-to-TBHP was sufficient for the good conversion of styrene.

The amounts of catalyst were also varied from 0.025 to $0.100 \mathrm{~g}$ keeping the other parameters constant (Table 1, entries 4 and 9,10$)$. With the increase in catalyst amount from 0.025 to $0.050 \mathrm{~g}$ the conversion of styrene increases from $53 \%$ to $95 \%$. Conversion of styrene was almost same with further increase of catalyst amount to $0.10 \mathrm{~g}$. A blank experiment in the presence of oxidant and using the same experimental conditions in the absence of the catalyst was also investigated in the oxidation of styrene. The obtained results showed that TBHP has poor ability to oxidize the styrene in absence of catalyst (entry 13).

Thus, the optimized operating conditions for the maximum oxidation of styrene was concluded as follows: styrene ( $5 \mathrm{mmol})$, TBHP $(10 \mathrm{mmol})$, water $(10 \mathrm{~mL})$, catalyst $(0.05 \mathrm{~g})$, and temperature $\left(60^{\circ} \mathrm{C}\right)$. The catalyst was efficiently converted both cyclic and linear alkenes such as cyclohexene, cyclooctene, transstilbene, 1 -hexene, $\alpha$-pinene, limonene and substituted styrenes under the optimized reaction conditions and gave selectively allylic oxidation product (Table 2, entries 2-9). In the oxidation of cyclohexene and cyclooctene, allylic oxidation products

Table 2. Olefins oxidation using PS-Ni-AMP catalyst ${ }^{a}$

\begin{tabular}{|c|c|c|c|c|c|}
\hline Entry & Olefins & Conversion $^{b}(\%)$ & Product (Selectivity) (\%) & Time $(\mathrm{h})$ & $\operatorname{TOF}\left(\mathrm{h}^{-1}\right)$ \\
\hline 1 & Styrene & 95 & $\begin{array}{l}\text { Benzaldehyde (93) } \\
\text { Acetophenone (7) }\end{array}$ & 8 & 424.0 \\
\hline 2 & Cyclohexene & 92 & $\begin{array}{l}\text { 2-cyclohexene-1-one (84) } \\
\text { 2-cyclohexene-1-ol (14) }\end{array}$ & 8 & 410.7 \\
\hline 3 & Cyclooctene & 78 & $\begin{array}{l}\text { 2-cyclooctene-1-one (79) } \\
\text { 2-cyclooctene-1-ol (13) }\end{array}$ & 10 & 278.6 \\
\hline 4 & trans-Stilbene & 72 & $\begin{array}{l}\text { Benzaldehyde (88) } \\
\text { Benzophenone (10) }\end{array}$ & 10 & 257.1 \\
\hline 5 & 1-Hexene & 52 & 2-hexanone (100) & 8 & 232.1 \\
\hline 6 & $\alpha$-Pinene & 69 & $\begin{array}{l}\text { Verbenone (76) } \\
\text { Verbenol (24) }\end{array}$ & 12 & 205.4 \\
\hline 7 & Limonene & 58 & $\begin{array}{c}\text { Carvenone (87) } \\
\text { Carvenol (12) }\end{array}$ & 12 & 172.6 \\
\hline 8 & 4-Methylstyrene & 92 & $\begin{array}{l}\text { 4-Methyl benzaldehyde (90) } \\
\text { 4-Methylacetophenone (12) }\end{array}$ & 8 & 410.7 \\
\hline 9 & 4-Chloro styrene & 94 & $\begin{array}{l}\text { 4-Chloro benzaldehyde (88) } \\
\text { 4-Chloroacetophenone (15) }\end{array}$ & 8 & 419.6 \\
\hline
\end{tabular}

${ }^{a}$ Reaction conditions: catalyst $(0.05 \mathrm{~g})$, substrate $(5 \mathrm{mmol}), \mathrm{H}_{2} \mathrm{O}(10 \mathrm{~mL})$, TBHP $(10 \mathrm{mmol})$, Temperature $60{ }^{\circ} \mathrm{C} .{ }^{b}$ Determined by GC and GC-MS. 
Table 3. A comparison of styrene oxidation by PS-Ni-AMP catalyst with other nickel catalysts reported in literature

\begin{tabular}{ccc}
\hline Catalyst & Reaction conditions & Conversion \\
\hline PS-Ni-AMP & $\mathrm{H}_{2} \mathrm{O}, \mathrm{TBHP}, 8 \mathrm{~h}, 60{ }^{\circ} \mathrm{C}$ & 95 \\
$\mathrm{NiL}^{2+} /$ mont. & $\mathrm{CH}_{2} \mathrm{Cl}$, TBHP, $6 \mathrm{~h}$, reflux & 17 \\
{$\left[\mathrm{Ni}\left(\mathrm{malonate}_{2}\left(\mathrm{H}_{2} \mathrm{O}\right)_{2}\right]_{\mathrm{n}}\right.$} & $\mathrm{ACN}, \mathrm{TBHP}, 68-70{ }^{\circ} \mathrm{C}, 12 \mathrm{~h}$ & 65 \\
$\mathrm{NiCl}_{2}$ & $\mathrm{H}_{2} \mathrm{O}, \mathrm{TBHP}, 8 \mathrm{~h}, 60{ }^{\circ} \mathrm{C}$ & 37 \\
\hline
\end{tabular}

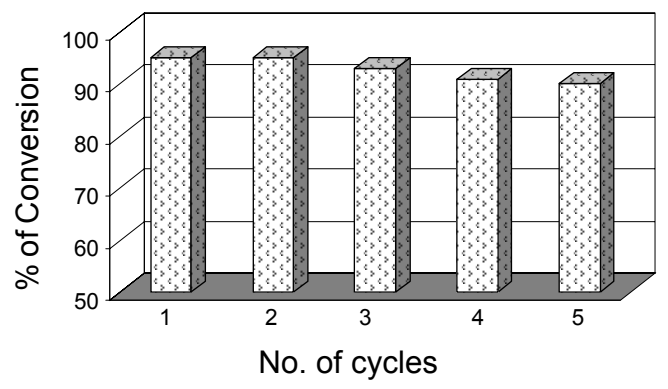

Figure 7. Recycling efficiency of [PS-Ni-AMP] catalyst for the oxidation of styrene.

2-cyclohexene-1-one and 2-cyclohexene-1-ol and 2-cyclooctene-1-one and 2-cyclooctene-1-ol were produced respectively. Trans-stilbene was oxidized by this heterogeneous catalyst in high yields to benzaldehyde as major product with small amount of benzophenone. Limonene selectively oxidized to carvone and carveol with small amount of other coproducts. This catalytic system showed a good activity in the case of $\alpha$ pinene. In the oxidation of $\alpha$-pinene, the major products were verbenone and verbenol. Substituted styrenes also gave high yield of oxidized product.

Further, we have compared the activity of the [PS-Ni-AMP] catalyst in the oxidation reaction with the other reported catalysts. The major advantage of our catalyst is that it shows high catalytic activity in environmentally friendly water medium. The results presented in Table 3 shows that our catalyst is superior to the other reported nickel catalyst i.e. $\mathrm{NiL}^{2+} / \mathrm{mont}^{20}$ and $\left[\mathrm{Ni} \text { (malonate) }\left(\mathrm{H}_{2} \mathrm{O}\right)_{2}\right]_{\mathrm{n}}{ }^{32}$ in terms of reaction time, reaction temperature and conversion. The catalytic activity of the present catalyst was also compared with homogeneous $\mathrm{NiCl}_{2}$. The activity of the present catalyst is also higher than corresponding metal chloride.

One of the main reasons of supporting a homogeneous metal complex on the polymer is to enhance the life of the resulting catalyst. The reusability of the present catalyst was checked in sequential oxidation of styrene. After initial run, the catalyst was separated by filtration, washed thoroughly, dried under vacuum and then subjected to the next run under the same reaction conditions. The catalyst was reused up to five times (Fig. 7), without significant loss of its catalytic activity. The amount of $\mathrm{Ni}$ in the recovered catalyst was determined by atomic absorption spectroscopy showed that the metal content of the recovered catalyst remains almost constant $(1.61 \mathrm{wt} \%$ of $\mathrm{Ni})$ even after fifth run. IR and UV-vis spectrum of the reused catalyst is quite similar to that of fresh sample indicating that the composition of the catalyst does not change after repeating use of ca- talyst.

A hot-filtration test was performed in the oxidation of styrene. After completion of the reaction, the solid catalyst was filtered off and the filtrate was tested in another reaction cycle. No conversion was detected in the filtrate. AAS analysis of the filtrate indicates absence of metal in the filtrate, confirming the truly heterogeneous nature of the polymer-supported catalyst.

\section{Conclusion}

We have demonstrated for the first time, the selective oxidation of olefins in presence of [PS-Ni-AMP] catalyst in water medium with TBHP (70\% aqueous), thereby meeting the dual challenge of cost effectiveness and environmentally benign process. In case of styrene oxidation benzaldehyde is the major product $(93 \%)$ with a maximum conversion of $95 \%$. All other olefins also yield selectively allylic oxidation product. The main advantages of the [PS-Ni-AMP] catalyst are that the synthesis is very simple, it does not need complicated equipment, the catalytic reactions can be conveniently carried out in air, and the separation of this heterogeneous catalyst can be achieved easily by filtration. The catalyst can be recycled five times without much loss in its activity.

Acknowledgments. We thank the Department of Material Science, Indian Association of Cultivation of Science, Kolkata, for providing the instrumental support. MI acknowledges DST, CSIR and UGC, New Delhi, India for funding.

\section{References}

1. Clark, J. H.; Tavener, S. J. Org. Process Res. Dev. 2007, 11, 149.

2. Li, C. J. Green Chem. 2008, 10, 151.

3. Azizi, N.; Aryanasab, F.; Torkiyan, L.; Ziyaei, A.; Saidi, M. R. J. Org. Chem. 2006, 71, 3634.

4. Horvath, I. T. Green Chem. 2008, 10, 1024.

5. Pirrung, M. C. Chem. Eur. J. 2006, 12, 1312.

6. Shapiro, N.; Vigalok, A. Angew. Chem., Int. Ed. 2008, 47, 2849.

7. Starks, C. M. J. Am. Chem. Soc.1971, 93,195.

8. Regen, S. L. J. Am. Chem. Soc. 1976, 98,6270

9. Meunier, M. Chem. Rev. 1992, 92, 1411.

10. Sherrington, D. C., Hodnett, B. K., Keybett, A. P., Clark, J. H., Smith, K., Eds.; Supported Reagents and Catalyst in Chemistry; Royal Society of Chemistry: Cambridge, 1998; p 220.

11. Islam, M.; Mondal, P.; Mukherjee, S.; Mobarak, M.; Roy, A. S.; Mondal, S.; Sarkar, S. J. Chem. Technol. Biotechnol. 2010, 85, 460.

12. Sherrington, D. C. Pure Appl. Chem. 1988, 60, 401.

13. Annis, D. A.; Jacobson, E. N. J. Am. Chem. Soc. 1999, 121, 4147.

14. Canali, L.; Sherrington, D. C. Chem. Soc. Rev. 1999, $28,85$.

15. Sherrington, D. C. Catal. Today 2000, $57,87$.

16. Islam, M.; Mondal, P.; Mondal, S.; Mukherjee, S.; Roy, A. S.; Mobarak, M.; Paul, M. J. Inorg. Organomet. Polym. 2010, $20,87$.

17. Valodkar, V. B.; Tembe, G. L.; Ravindranathan, M.; Ram, R. N.; Rama, H. S. J. Mol. Catal A: Chem. 2004, 208, 21.

18. Mukherjee, S.; Samanta, S.; Bhaumik, A.; Roy, B. C. Appl. Catal. B Environ. 2006, 68, 12

19. Mukherjee, S.; Samanta, S.; Roy, B. C.; Bhaumik, A. Appl. Catal. A Gen. 2006, 301, 79.

20. Sohrabi, H.; Esmaeeli, M.; Farzaneh, F.; Ghandi, M. J. Inclusion Phenomena and Macrocyclic Chem. 2006, 54, 23.

21. Sheldon, R. A.; Kochi, J. K. Metal Complex Catalyzed Oxidation of Organic Compounds; Academic Press: New York, 1981. 
22. Cainelli, G.; Cardillo, G. Chromium Oxidation in Organic Chemistry; Springer-Verlag: New York, 1984.

23. Kroschwitz, J. I.; Othmer, K. Encyclopedia of Chemical Technology; Wiley-Interscience: New York, 1992.

24. Ullmann, F. Ullmanns Encyclopedia of Industrial Chemistry; Wiley-VCH: Verlag, Weinheim, Germany, 2003.

25. Gokak, D. T.; Kamath, B. V.; Ram, R. N. J. Appl. Polym. Sci. 1988, $35,1523$.

26. Angelino, M. D.; Laibinis, P. E. Macromolecules 1998, 31, 7581.

27. Antony, R.; Tembe, G. L.; Ravindranathana, M.; Ram, R. N. Eur.
Polym. J. 2000, 36, 1579.

28. Bellamy, L. J., Ed.; Infra-red Spectra of Complex Molecules; Chapman and Hall: London, 1975.

29. Gauli, K.; Ram, R. N.; Soni, H. P. J. Mol. Catal. A: Chem. 2005, 242,161 .

30. Colchoubian, H.; Waltz, W. L.; Quail, J. W. Can. J. Chem. 1999, $77,37$.

31. Sacconi, L. Trans. Met. Chem. 1968, 61, 943.

32. Sen, R.; Bhunia, S.; Mal, D.; Koner, S.; Miyashita, Y.; Okamoto, K. Langmuir 2009, 25, 13667. 